\title{
Yield Management in the French Hotel Business: An Assessment of the Importance of the Human Factor
}

\author{
Noureddine Selmi \\ Esc La Rochelle \\ 2 allée E. Bouchardon, 17000 La Rochelle, France \\ Tel: 33-5-4651-7700 E-mail: selmin@esc-larochelle.fr \\ Raphaël Dornier (corresponding author) \\ Isc Paris \\ 22 Bd du Fort de Vaux, 75017 Paris, France \\ Tel: 33-1-4053-9999 E-mail: rdornier@groupeisc.com
}

Received: January 29, 2011 Accepted: February 18, 2011 doi:10.5539/ibr.v4n2p58

\begin{abstract}
Based on a qualitative study of the practice of Yield Management in the hotel industry, and semi-direct exploratory interviews with 27 Paris hotel managers, this study highlights the strong connection between Yield Management and information systems, and stresses the great importance of the role played by the human factor in the establishment and development of an effective Yield Management system.
\end{abstract}

Keywords: Yield Management, Human resources, Hotel industry, Qualitative study

\section{Introduction}

Under current conditions, with the market in crisis, hotel managements are increasingly turning to technology and computer applications for decision-support tools, for example Yield Management (YM in the rest of the article), seeking a better way to manage their occupancy and optimize their income. However, YM is not a new technique. In fact, the techniques of YM have been attracting attention from numerous researchers and practitioners for more than two decades. Although its techniques have been extensively documented on the theoretical level, especially in the air-transport sector, their application and development in the hotel industry have received little attention. In order to enhance our understanding of the technique in this area, and to identify the variables and factors affecting its introduction, development, and successful use, we have employed an exploratory approach based on a qualitative methodology. Our study particularly addresses the human factor and its importance for the success of these techniques, now seen as inescapable components of the information systems of hotel organizations.

Although the introduction of new technologies has limited the scope of human intervention in certain occupations, in others it has made possible a higher level of skill, an increased responsiveness, and a greater efficiency. In this connection, YM techniques provide a type example for studies of the interaction between Man and technology. This study is intended to provide a better understanding of the role played by the human factor in the application of new technologies. Are YM techniques capable of replacing human decisions, or do they instead serve to complete and refine our own decisions on the pricing of services? In this study we will pay particular attention to human involvement in the adoption of YM techniques by French hotels.

\section{Description of Yield Management in the hotel business}

YM has been defined in a number of ways. However, its purpose is simple. It is to provide better management of a limited available capacity (such as airline seats or hotel rooms), so as to maximize overall income by applying a flexible pricing policy (Desiraju and Shugan, 1999) based on a segmentation of the supply (Desmet and Zollinger, 2000). The most widely accepted definition is that proposed by Smith, Leimkhuler, and Darrow (1992). They suggest that "YM is a sophisticated way of managing supply and demand by acting simultaneously on the prices and the available capacity. It is a process of allocating the best service to the best customer at the best price and at the best time". 
Since the 1980s, YM has been extended far beyond airline pricing. Although it initially focused on modeling, the literature subsequently concentrated primarily on the applicability of this technique to other activities (Jallat and Ancarani, 2008), particularly ones that combined a certain number of conditions (Kimes, 1989). The hotel business is one of the areas that meets this requirement, and provides a context that is very favorable for the application of Yield Management techniques (Lehu, 2000).

However, as recommended by Guilloux (2000) among others, research on YM must be carried out in a more general manner, taking into account the many factors affecting its implementation and success. It would seem wise to consider first its interactions with the hotel organization's information system and human resources.

\subsection{Yield management and information systems in the hotel business}

According to Perrien and Ricard (1994), the organizational structure and level of technological development in which a hotel is situated directly affect its chances of successfully implementing a YM system. Along with several other authors (e.g., Warren and Ostergren, 1990; Yucelt and Marcella, 1996), Daigle and Ricard (2000) found that the use of information systems, and especially those that employ databases, was essential for the successful implementation of a YM system.

According to MacVicar and Rodger (1995), the use of computerized systems in hotels was inevitable. Management reports prepared without computer support would be too incomplete and would not allow the various market segments to be handled. In cases where capacity is limited and demand fluctuates widely, Gamble (1990) considered that the use of new information technologies to manage the available supply was essential.

If we take into account all the variables that a hotel must consider if it is to arrive at the best solution (different categories of guests, different rates, a variety of options, sales restrictions, etc.), it becomes evident that our limited human cognitive capacities will never, by themselves, be able to identify the optimal decision. Some decisions require a choice among a variety of risks that are difficult to apprehend or measure.

Sophisticated computing tools then become essential for improving the management of capacity. YM programs allow the processing of large databases replete with information on the history of the organization's activities, consumer behaviors, and the competition. This enables more accurate forecasting and the efficient, real-time management of sales. According to Lehu (2000), effective YM cannot be achieved without the use of sophisticated modeling closely adjusted to the company's activity, and usually supported by a powerful information-processing system. Computers allow us to make accurate and impartial forecasts, more in line with reality.

However, in order for YM to generate a real increase in earnings it has to be understood, learned, and above all accepted by every member of the organization (Farell and Whelan-Ryan, 1998). Poor communication between the various operating departments, a lack of understanding of YM's principles, or resistance to implementing these techniques can lead to a substantial opportunity cost. A YM system will not be of benefit to an hotel if individual employees do not effectively manage the recommendations that the tool provides.

\subsection{Yield Management as a human activity}

Yeoman (1996) describes YM as a system of human activity. This position is supported and discussed by Yeoman and Wateson (1997) among others. They confirm that the management process created by a YM system is basically a human activity, and that its results depend mainly on the team in charge of it. According to Daigle and Ricard (2000), when we speak of a relational approach in the hotel business we are really talking about YM. Thus the success of a Yield-Management system appears to be directly related to the human factor.

One of the factors in the success or failure of the use of YM in an organization is to be found in the intelligent use of its abilities for booking and overbooking. This assumes that the personnel is qualified and responsive (Hendler and Hendler, 2004). YM is not just a piece of software that, once installed, will function automatically. Rather, it is a method of management which managers and employees alike must be trained to use (Liberman, 2003). The main decision that the personnel responsible for reservations must make consists of choosing between two alternatives which can be summarized simply as: should I sell this unit now at this price, or should I wait in case a customer comes along who will agree to a higher price? Each of the two decisions presents a risk. If the company turns down a booking at a lower price, hoping to sell the service (room, seat, etc.) at a higher one, it risks finding itself with unsold services: this is the risk of waste. The reverse situation consists of accepting the reservation, thereby losing later customers ready to pay a higher price: this is the risk of rejects. A third decision, arising from the practice of overbooking, involves a risk of refusal. This risk occurs when the number of services sold in excess of the capacities exceeds the number of cancellations. The company is then forced to refuse customers who have made bookings, or even paid in advance. 
The personnel have to manage the bookings and optimize the rate of overbooking allowed in each price category so as to minimize the resulting risks. The choices made between the three risks (waste, rejects, and refusal) directly affect the functioning of the YM system and thus the result obtained (Daudel and Viall, 1994; Capiez, 2003). YM techniques, in particular the appearance of the occupation "Yield \& Revenue Manager", mark the end of decisions based on intuition and chance. Naturally it is still necessary to make use of the experience, skills, and common sense of men and women, but they all need to be supplemented by new technologies (computer tools and programs) of an ever more innovative nature.

A YM system does not take away a manager's autonomy of decision (Liberman, 1993). The expertise of a person who can accept or reject bookings remains essential for detecting possible drifts in the system under particular conditions, such as the mistaken refusal of a booking from a business customer or a regular patron. In these cases the manager is free to ignore the recommendations made by the system (MacVicar and Rodger, 1995). Meticulously following the system's recommendations can lead to problems, because the system does not address factors that are difficult to quantify - for example, no priority is assigned to a regular customer. However, it should be noted at this point that the recommendations supplied by the system are generally effective in substantially reducing the margin of error, compared with situations in which this technology is not available.

Among the seven principles set out by Cross (1998) which the organization should adopt when implementing YM techniques, we consider that two are of fundamental importance. (1) The use of reliable information, which means that it is necessary to compile vast quantities of detailed information and store it in historical databases. However, this may not be a real decision-support system if the information is not applied in a relevant manner. The information must therefore be processed in light of the market in order to predict future changes in consumer demand. A reliable forecast must anticipate what will happen, regardless of what people believe or what they would like to happen. Managerial intuitions can turn out to be wrong. Even experienced managers rarely display a perfect impartiality. Only a computer with an appropriate program can adequately formulate reliable predictions. (2) Training and involving the personnel: YM does not take the place of managers in making decisions; it is primarily a tool for supporting decisions. The role of the personnel will in no way be diminished in companies that adopt these techniques. On the contrary: it will become more important than ever. The computers will take over a significant portion of the work: the collection, processing, and distribution of data, and the sorting and filtering of information. The managers will complete this work by performing the critical analyses and making the decisions.

\section{Methodology}

As part of this exploratory study, semi-direct face-to-face interviews were carried out. We prefered to choose a qualitative study in order to explore in depth the perceptions of managers and to identify possible differences between them. We also believed that a quantitative study based on a questionnaire may bias the results of our study by limiting the scope and the diversity of their answers. To truly understand their opinions without orientating them we therefore decided to lead face to face interview with open questions. We conducted these interviews with a sample of 27 senior managers in 20 hotels in Paris and its environs (Appendix A). To ensure the confidentiality of the information, the interviewees were not identified, and the 20 hotels were accordingly designated $\mathrm{H} 1, \mathrm{H} 2$, etc. (Appendix A). Our sample then comprises 27 individuals. We interviewed 18 persons from management (15 hotel managers, one assistant manager, and two operations managers). The other persons interviewed were YM managers in their respective hotels (two revenue managers, five yield managers, one reservations manager, and one hospitality manager). In some hotels we interviewed more than one manager (two to three persons in seven hotels). The main objective of these interviews was to obtain a more detailed understanding of the components of a successful adoption of YM, and of the development of YM techniques in the hotel sector.

The 20 hotels making up our sample are of medium to large size (the smallest has 40 rooms and the biggest 736 , the average capacity being 247 rooms). All the hotels we visited are in the two- to four-star luxury category (Appendix A). The choice of Paris and of hotels with relatively large capacities was necessary in order for the hotels to possess and apply a YM system. All the interviews with the 27 managers were conducted by using an interview guide endorsed by an expert in the hotel sector and a professor of marketing.

The interview guide was limited to four general topics related to the implementation and development of YM in the hotel business. The interviews had an average duration of 65 minutes (from a minimum of 35 minutes to a maximum of 2 hours 30 minutes). Apart from one hotel manager who preferred not to be recorded, all the interviews were taped. Recording the interviews made possible an almost total re-transcription of the interviewees' words. We then grouped the manager's opinions by topic, and used these groupings to obtain the following main results. This methodology was close to the one of content analysis (eg Bardin, 2007) that is often used in the study of individual perceptions. Nevertheless we decided not to use a pre-defined list of themes identified from the literature 
but rather to let the themes emerge from the analysis of the interviews, in order to be consistent with the exploratory perspective we chose for this study. When we considered that two themes identified in the answers of different managers were close to each other, we decided to group them together by creating a more general theme. We then associated verbatim with each of the final themes we identified.

\section{Results and discussion}

The main objective of this work is to identify the decisive factors in the successful implementation of a YM system, by means of an exploratory qualitative study. In formulating our recommendations we relied on the existing literature, and on interviews conducted with hotel managers. The comments of the interviewees lead to four recommendations for the optimum use of a YM system, all directly connected to the human factor. The principal results are:

\subsection{Management commitment}

The commitment and motivation of management are decisive in the implementation of a relational approach (Wilson 1995). The words of the interviewees in our sample, especially the passages quoted in Appendix B, confirm this result. These managers consider that the commitment of the management is very important for the successful implementation of a YM system. Management must initiate the introduction of YM, closely monitor its operation, and be fully involved if the outcome is to be successful. They also recommend that the hotel manager and the Yield Manager work together to determine the hotel's strategy.

A firm commitment from management to succeed in this organizational change needs to be based on its conviction that such a system is necessary and worthwhile.

\subsection{Importance of a YM system}

The testimony presented in Appendix $\mathrm{C}$ shows that the interviewees are unanimous concerning the importance of these techniques. YM is found to be beneficial, profitable, useful, opportunistic, effective... which makes it a necessary, even essential tool: no hotel manager can do without it. These words recur frequently in the collected comments, and the interviewees back them up. The managers consider that these techniques provide food for discussion and bring valuable recommendations as well as significant profits arising from more accurate predictions.

These results corroborate the work of MacVicar and Rodger (1995), who found that the use of a YM system enables the personnel to "transform themselves" by becoming familiar with these techniques. Several other authors, e.g., Liberman, 1993, find that a YM system allows for more formalized decisions. These computerized tools enable a simpler control of the decisions taken, and reduce the number of errors. The dominant view is that the system strengthens the position of the decision-maker, and brings greater precision to the actions undertaken. All of the managers interviewed state that they are convinced of the substantial contributions made by a YM system to improving the utilization of information.

\subsection{Contribution made by the tool (software program)}

According to the managers interviewed (Appendix D), a Yield Manager cannot properly do his or her work without having a YM program. According to Liberman (1993), any YM system must be based on a sophisticated mathematical model. Indeed, without the computer and the application of a software program, the best results obtainable from YM will never be achieved, because only a computer can provide good forecasts of the demand, cancellations, no-shows, walk-ins, etc. It makes recommendations for restrictions, estimates the probable income from the displaced demand, checks availabilities, provides proposals for managing groups and durations of stay, and so on.

A YM program is thus an excellent optimization tool. It offers the person in charge (ideally a Yield Manager) a continuous response to the moment-to-moment changes occurring in the data, and a more accurate long-term overall view. The automatic processing of information provides enormous savings in terms of time, and excellent reliability in the information available for immediate use.

\subsection{The major importance of the human factor}

Our interviews (Appendix E) show that in order to successfully implement a YM system, the personnel must be properly trained. According to Guilloux (2000), Yield-Management training must be provided at the technical, philosophic, and cultural levels. Not only is it critically important that reservation managers be trained in the techniques and concepts of YM, but also hotel managers. According to Yeoman and Watson (1997), the process of controlling the system is essentially a human activity. Having personnel who are well trained in Yield-Management techniques will enable the hotel to seize opportunities and contribute to the successful application of the system. Proper training of the person in charge is therefore indispensable. Our interviews also confirm the findings of 
Bradley and Ingold (1993) who, based on an analysis of the views of the hotel personnel they interviewed, found that it was more difficult to train managers in YM techniques without using a computer. Using a computer as a tool for training considerably reduces the perceived difficulty and complexity, because people will view these techniques as an extension of their daily tasks.

The great importance of the computer tool and the value of a YM program can then be recognized by hotel managers. However, we found that the 27 persons in our sample were unanimous in saying that the use of YM is, in the first instance, a common-sense business. To manage better and to make the necessary decisions requires capable, adaptable people, with trained teams that are able to respond quickly and effectively.

The program provides statistics, forecasts, figures, and sometimes also recommendations. But when it comes to accepting or rejecting a reservation, and for choosing among a number of risks, it is men and women who decide. The human component is therefore far from being negligible. On the contrary, it is more important than ever. Moreover, the creation of the position of "Yield \& Revenue Manager" and its ever-growing importance in the hotel business is an illustration of this discussion.

A mere commitment by the management will not enable the implementation of an appropriate YM system. If the personnel do not share the same motivation the result may be disappointing, and sometimes even contrary to the objectives. A successful move to a YM system requires that every stage of the implementation process be completed. This process is essentially based on knowledge, acceptance, and training.

At the end of this endeavor, it is necessary to grasp its managerial scope. Our study confirms the main results of previous studies in non-French environments. As emphasized in the study by Daigle and Ricard (2000) among others, major hotels succeed in being "relational" by using and controlling information technologies.

Of course, in the hotel business decisions must take into account the managers' experience and their knowledge of the market and of the profiles of each type of customer. However, using only intuition and "common sense" will not lead to the optimized management of what a hotel has to offer. Under current market conditions, and especially during a crisis, acquiring sophisticated statistical-analysis tools has become a sine qua non for having a more profitable and competitive hotel.

The comments gathered in the interviews confirm the fundamental importance of the fact that these new YM techniques must be accepted by all of the teams (management, reservations, reception, and other). A commitment by all the parties involved, based on a firm belief in the usefulness and importance of the system and accompanied by quality training of the personnel, are prerequisites for managing a hotel under a YM system.

\section{Conclusion}

We believe that our research has contributed to the debate concerning (i) the importance of the adoption and development of YM techniques in hotels, and (ii) the absolute necessity of human resources capable of backing up this organizational change. It appears that the human factor is critical to the implementation of an effective YM system. Although YM has been described in many articles as a technique that makes possible accurate predictions of the behavior of demand, which can lead to higher earnings, this can really only be achieved if the results produced by the system are carefully interpreted by personnel trained to make the necessary decisions. Lastly, the success of yield management in a hotel requires the commitment of essentially all of the personnel, and a close inter-departmental coordination.

However, a broader application of the results of this study may be difficult, for several reasons, the main one being that the majority of the hotels studied belong to a chain or group of hotels. This study attempts to make a contribution to the debate on the importance of the human factor in the success of a new decision-support system. Additional research is needed to supplement it, in particular by examining broader samples and/or interviewing a number of persons occupying different positions in hotels employing YM.

\section{References}

Badinelli, R D. (2000). An Optimal Dynamic Policy for Hotel Yield Management. European Journal of Operational Research, 121, 476-503.

Bardin, L. (2007). L'analyse de contenu, PUF.

Bradley, A, \& Ingold, I. (1993). An investigation of yield management in Birmingham hotels. International Journal of Contemporary Hospitality Management, $3: 2,13-16$.

Capiez, A., (2003). Yield Management: Optimisation du Revenu dans les Services. Hermes Science Publications.

Cross, R. G. (1998). La Tarification Flexible. Les Editions d'Organisation. 
Daigle, A. \& Ricard, L. (2000). L'approche relationnelle dans le secteur hôtelier, une étude exploratoire. 16th congrès international de l'Association Française du Marketing, Montréal, Canada.

Daudel, S. \& Viall, G. (1994). Yield Management- Applications to air transport and other service industries. Les presses de l'Institut de Transport Aérien: Paris.

Desiraju, R. \& Shugan, S. (1999). Strategic service pricing and Yield Management. Journal of Marketing, 63, 44-56.

Desmet, P. \& Zollinger, M. (2000). Le prix de l'analyse conceptuelle aux méthodes de fixation. Economica: Paris.

Dubois, P. L. \& Frendo, M. C. (1995). Yield Management et Marketing des Services. Décisions Marketing, Janvier-Avril, 47-54.

Farell, K. \& Whelan-Ryan, F. (1998). Yield Management: A Model for Implementation. Progress in Tourism and Hospitality Research, 4, 267-277.

Fitzsimmons, J. A. \& Fitzsimmons, M. J. (1999). Service Management, Operations, Strategy, and Information Technology. McGraw-Hill.

Gamble, P. R. (1990). Building a yield management system, the flip side. Hospitality Research Journal, 14: 2, 11-21.

Guilloux, V. \& Beluze, G. (2002). Revenue Management par Place: une Spécificité Accor. Décisions Marketing, 26, 7-15.

Guilloux, V. (2000). Le Yield Management: concepts, méthodes et enjeux stratégiques. Recherche et Applications en Marketing, 15: 3, 56-73.

Hendler. R, \& Hendler, F. (2004). Revenue Management in fabulous Las Vegas: Combining customer relationship management and revenue management to maximize profitability, Journal of Revenue and Pricing Management, 3: 1, 73-79.

Jallat, F., \& Ancarani, F. (2008). Yield management, dynamic pricing and CRM in telecommunications. The Journal of Services Marketing, 22: 6, 465-478.

Jauncey. S., Mitchell I., \& Slamet P. (1995). The Meaning and Management of Yield in hotels. International Journal of Contemporary Hospitality Management, 7: 4, 23-26.

Kimes, S. (1989). The Basics of Yield Management. The Cornell Hotel and Restaurant Administration Quarterly, 30: 3, 14-19.

Lehu, J. M. (2000). Internet comme outil de Yield Management dans le tourisme. Décisions Marketing, 19, 7-19.

Liberman, W. H. (1993). Debunking the Myths of Yield Management. The Cornell H.R.A. University, 2, 34-41.

Liberman, W. H. (2003). Getting the most from Revenue Management, Journal of Revenue and Pricing Management, 2: 2, 103-115.

Luciani, S. (1999). Implementing Yield Management in Small and Medium Sized Hotels: An Investigation of Obstacles and Success Factors in Florence Hotels. International Journal of Hospitality Management, 18: 2, 129-142.

MacVicar, A, \& Rodger J. (1995). Computerized yield management systems: a comparative analysis of the human resource management implications. Paper from the IAHMS Conference Gothenburg.

Perrien, J., Ricard Icard, L. (1994). L'approche Relationnelle dans le Secteur Bancaire. Revue Gestion, Décembre, 21-26.

Smith, B., Leimkuhler, J., Darrow, R. \& Samules J. (1992). Yield Management at American airlines. Interface, 1, $8-31$.

Warren, P., Ostergren, N. W. (1990). Marketing Your Hotel: Challenges of the '90s. The Cornell Hotel and Restaurant Administration Quarterly, May, 56-59.

Wilson, D. T. (1995). An Integrated Model of Buyer-Seller Relationships. Journal of the Academy of Marketing Science, 23: 4, 335-345.

Yeoman I. \& Watson, S. (1997). Yield Management a human activity system. International Journal of Contemporary Hospitality Management, 9: 2, 80-83.

Yoeman, I. S. (1996). A Conceptual Model of Yield Management. Unpublished Paper Napier University Edinburgh.

Yucelt, U. \& Marcella, M. (1996). Services Marketing in the Lodging Industry: An Empirical Investigation. Journal of Travel Research, 48, 32-38. 
Table 1. Hotel sample studied and managers interviewed

\begin{tabular}{|c|c|c|c|c|c|c|}
\hline $\begin{array}{l}\text { Hotel } \\
\text { code }\end{array}$ & Mgrs. Interviewed & $\begin{array}{c}\text { Category } \\
\text { (in *) } \\
\end{array}$ & Capacity & Number of hotels & $\begin{array}{c}\text { Number of } \\
\text { Pers. }\end{array}$ & Duration \\
\hline H 1 & $\begin{array}{c}\text { Manager } \\
\text { D-H1 }\end{array}$ & 3 & 147 & 1 & 1 & $70 \mathrm{~min}$ \\
\hline $\mathrm{H} 2$ & Manager D-H2 & 2 & 61 & 1 & 1 & $70 \mathrm{~min}$ \\
\hline $\mathrm{H} 3$ & Yield Manager YM-H3 & 4 & 736 & 1 & 1 & 1 hour \\
\hline $\mathrm{H} 4$ & Manager D-H4 & 3 & 144 & 1 & 1 & $1 \mathrm{hr} 25 \mathrm{~min}$ \\
\hline H 5 & $\begin{array}{c}\text { Yield Manager YM-H5 } \\
\text { \& Assistant Manager } \\
\text { D-H5 }\end{array}$ & 4 & 116 & 1 & 2 & $1 \mathrm{hr}$ \\
\hline H 6 & Manager (former YM) D-H6 & $4 \& 3$ & 40 & 3 & 1 & $1 \mathrm{hr}$ \\
\hline H 7 & $\begin{array}{c}\text { Manager D-H7 } \\
\text { Yield Manager YM-H7 } \\
\text { \& Ops. Manager DE-H7 }\end{array}$ & 3 & 364 & 1 & 3 & $1 \mathrm{hr}$ \\
\hline $\mathrm{H} 8$ & Manager D-H8 & 4 & 146 & 1 & 1 & $50 \mathrm{~min}$ \\
\hline H 9 & $\begin{array}{c}\text { Manager D-H9 } \\
\text { \& Reservations Mgr. } \\
\text { YM-H9 } \\
\end{array}$ & 3 & 118 & 1 & 2 & $40 \mathrm{~min}$ \\
\hline $\mathrm{H} 10$ & Manager D-H10 & 3 & 190 & 1 & 1 & $35 \mathrm{~min}$ \\
\hline $\mathrm{H} 11$ & Manager D-H11 & 2 & 300 & 1 & 1 & $40 \mathrm{~min}$ \\
\hline $\mathrm{H} 12$ & Yield Manager YM-H12 & 4 & 289 & 1 & 1 & $40 \mathrm{~min}$ \\
\hline $\mathrm{H} 13$ & Manager D-H13 & 2 & 326 & 1 & 1 & $40 \mathrm{~min}$ \\
\hline H 14 & $\begin{array}{c}\text { Manager D-H14 } \\
\& \text { Hospitality Manager YM-H14 }\end{array}$ & 2 & 700 & 1 & 2 & $50 \mathrm{~min}$ \\
\hline $\mathrm{H} 15$ & Manager D-H15 & 3 & 138 & 1 & 1 & $2 \mathrm{hr}$ \\
\hline H 16 & $\begin{array}{c}\text { Manager D-H16 \& } \\
\text { Yield Manager YM-H14 }\end{array}$ & 4 & 376 & 1 & 2 & $1 \mathrm{hr} 20 \mathrm{~min}$ \\
\hline $\mathrm{H} 17$ & Manager (10 hotels) D-H17 & 2 & 103 & 10 & 1 & $40 \mathrm{~min}$ \\
\hline $\mathrm{H} 18$ & 2 Revenue Managers H18 & & & several & 2 & $55 \mathrm{~min}$ \\
\hline H 19 & Manager D-H19 & 3 & 315 & 1 & 1 & $100 \mathrm{~min}$ \\
\hline H 20 & Manager D-H20 & 3 & 85 & 1 & 1 & $55 \mathrm{~min}$ \\
\hline TOTAL & 20 & From $2 *$ to $4 *$ & & & 27 & Av. $=61 \mathrm{~min}$ \\
\hline
\end{tabular}

Table 2. Management commitment

Manager H4: However, we're all convinced of the optimization we can obtain with ... I think now we've got the hang of it.

Manager H6: some managers have weekly meetings with their yield managers, and it's not a two-person team any more.

Manager H8: you also have to really trust it ..., now we can still make a mistake but that happens less and less often however! Even if we can't see the future, we have so many ways of getting quick information... I think that at a certain point, if it is properly supported, if it is well managed, there aren't a lot of possible errors.

Manager H11: it only has to be initiated and supported by management.

Manager H13: now, yield management is part of our way of operating.

Manager H15: for me, working on yield management means putting the hotel's strategy into practice.

Revenue Manager H18: yield management is an important part of the hotel... the revenue manager works directly for the management, an integral part of the management team... it's more than integral, and its more than a culture... the manager has to be fully involved with the yield manager, the top yield manager in the hotel is really the hotel manager... the managers have to understand this properly...

Manager H19: yield management is a clear, distinct strategy... yes, it's fully integrated... there are a lot of hotels that have recruited and created positions specifically tied to yield management.

Manager H20: Managers must follow through on the decisions of the yield managers, even if they don't agree with their advice, as long as the yield managers can show that their decisions make a contribution, 
Table 3. Perceived importance of Yield Management

Manager H1: an expert in this area makes a contribution, it adds something and creates a discussion... can give more accurate forecasts, it lets you adjust the strategy... recommendations and advice that are much more precise and valuable.

Manager H2: today, using yield management means always being opportunistic.

Yield Manager H3: yield management is a key factor, it's practically indispensable.

Manager H6: It's an excellent optimization tool ... it allows you to have a long-term view, an accurate view... it's a very useful tool... it allows you to have more accurate information and to have information available immediately.

Manager H7: we absolutely need .... yield management gives a better picture and teaches us to be as open as possible about the state of the market.

Manager H8: these days we definitely can't work without this tool... without it, it would be hard to do our job.

Manager H9: it's a tool that is really effective, you can feel it.

Manager H10: I'm convinced of its benefits now.

Manager H11: for us it's a basic item, personally I can't even imagine working without revenue management, too many mistakes, nowadays it's a useful analytical tool ... a very important tool.

Yield Manager H12: $i t$ 's a necessity in hotels.

Manager H13: allows us to have a perfect view of the future.

Manager H14: the more we use yield management the closer we get to the true picture ... it corrects us by having more experience

Manager H16: $i t$ 's an essential thing ... it's the extra that everyone needs.

Revenue Manager H18: I think it really pays off.

Manager H20: makes us think about our business approach, it's more a reminder about strategy ... it's part of the attraction of our work ... you have to admit that it's beneficial.

Table 4. Contribution of the tool_

Manager H1: but the tool has also contributed a lot, in fact there's an exchange, there's the tool that provides us with constraints and restrictions and we also bring things... for "strategic" hotels yield management is essential... so the more data we have concerning operations the more interesting strategic choices we can make ... A yield manager with a tool, for certain hotels that's a necessity.

Yield Manager H5: now there are tools that help us to make decisions and enable us to sharpen our decision-making.

Manager H6: it's an excellent optimization tool ... allows for extraordinary adaptability ... it gives you a long-term view, an accurate view ... it's a really useful tool ... it gives more accurate information and allows you to have the information immediately available... I think that everybody, all the hospitality people initially, but I believe that yield management has been developed beyond guest services, .... we need tools that are increasingly automated and increasingly sophisticated.

Manager H7: it's our basic working equipment; it enables us to be very very vigilant.

Manager H8: It's one of the things that we call decision-support tools ... in a few seconds the program gives us the help that several people would have trouble providing in several hours, because there are so many calculations to perform ... it's such a specialized occupation, with a need for effective tools to back it up.

Manager H9: it's now become a tool that's easy and quick to master, which helps us in our management.

Manager H10: the best definition I can give you: yield management is the technologic, digital, and mathematical application of common sense ... yield management is only a component, only a decision-support tool.

Yield Manager H12: the information-processing tool helps us...

Manager H14: experience in using this tool has shown us its finer points.

Manager H5: we're working with a computer system ... The system, the more we feed into it, the more it gives us good recommendations - it's a support for decision-making.

Manager H17: we now have tools that really let us get into the details of the matter (increasing load, sub-segmentation, typical days, etc.); really, it's very detailed. 
Table 5. Human Factor

Manager H1: it's a relatively new occupation ... in my opinion it's still a commonsense one. In the hotel business, most of the time it's a person who does yield management automatically, using common sense, and you give this person a tool that works fairly well, and by using these tools the person gets better at the job .... the position of yield manager, in my opinion it's not only more important now, but it's essential, I think that nowadays a hotel without a yield manager cannot function.

Manager H2: human factor ... to manage a hotel you need human beings, so it's the same for doing yield management, the team you have has to know how to respond, the people can't just sit there and do nothing ... So you have to train your team to be capable of responding.

Yield Manager H3: yield management: we're the ones who put it all together, using common sense to obtain reliable forecasts.

Manager H4: yield management is simply a matter of logic and common sense.

Manager H6: the job of yield manager in a hotel is very important ... in some hotels the yield manager is as important as the hotel manager, he's the one who decides the strategy, not the manager.... human activity, not forgetting that there is a human side that you must have when making reservations, taking risks - you mustn't overlook the human side.

Manager H8: it's one of the tools that we call decision supports, the person is still the only decision-maker, a machine is not going to dictate to us, rather it's there to help us make decisions ... a yield manager must be completely independent ... if you have a poor yield manager it can be a disaster ... it's an occupation which is very interesting, which has led to questions about all kinds of choices.

Reservations Manager H9: now, because we have this program, we need a dedicated person to manage it on a daily basis.

Manager H9: it's a tool and a system that makes the human function more effective.

Manager H10: we've established a new occupation: the "yield manager" ... Yield management all by itself wouldn't work, you also need the concept of common sense ... by introducing just one item into it: the human factor ... the human factor is very important in making yield management work.

Manager H11: there's a whole process of learning, of training and acceptance ... a human activity, the tool is only the databases, ultimately it's the person who does the interpretations and it's the person who takes the risks, so yes, it's the human being who decides.

Yield Manager H12: it's an exchange between man and machine.

Manager H15: what you have to remember is that the tool only makes recommendations, it's the manager who is in charge, because the system doesn't know the environment, the market, or the competition ... So the tool, sure, it's very good but you still have to know about the seasons of the year.

Manager H16: responsive, yes, you have to make decisions quickly.

Revenue Manager H18: yield management is above all common sense, but then, nowadays it's not enough because it has to be more scientific, you need something else, common sense plus scientific tools ... So yield management is basic common sense plus the scientific aspect: that makes for a good outcome.

Manager H19: it's like any tool, it has to be properly used ... you have to be very, very responsive.

Manager H20: adaptability, experience with people, the creative aspect, they're all essential ... you have to do it effectively. 